\title{
KONSENSUS KEBANGSAAN DALAM PERSPEKTIF PONDOK PESANTREN NGALAH
}

\author{
${ }^{1}$ Mifakhul Isnaini, ${ }^{2}$ Saifulah \\ ${ }^{1}$ mifakhul.isnaini@gmail.com, ${ }^{2}$ saifulah@yudharta.ac,id \\ ${ }^{2}$ Universitas Yudharta Pasuruan
}

Abstract: The country of Indonesia consists of various islands, tribes, arts and culture, languages and different religions. The difference is a unity within the framework of the Unitary Republic of Indonesia based on the Pancasila and the 1945 Constitution. However, there are some groups or groups who want and make efforts to change the basis of our beloved Indonesian State with the form of an Islamic State. The national consensus has become an important guide in maintaining the unity and integrity of the Indonesian nation in the course of history to date. Various incidents of betrayal in the form of rebellion, separatist movements, coup d'etat, even legal political struggles through the Constituent Assembly, were carried out by various community groups to change or replacing the consensus can be overcome. The results of this study indicate that: The boarding school does not make a distinction whether students live in a boarding house or not. They can learn from, interact with, and help one another and recognize the difference as reality. Kiai sholeh embodies the concept of interfaith relations with the formation of dialogue which he has held by holding a national seminar on interfaith harmony. The interpretation of the national seminar is the interaction of kiai sholeh with non-Muslims such as joint prayer, religious silaturrohmi, performing arts, live in 100 pastors, cooperation in education, cultural fusion, and social action of the nation's youth

Keyword: National Consensus, Boarding School 
Abstrak: Negara Indonesia terdiri dari berbagai pulau, suku, seni dan budaya, bahasa, dan agama yang berbeda-beda. Perbedaan tersebut merupakana satu kesatuan dalam bingkai Negara Kesatuan Republik Indonesia yang berasaskan Pancasila dan UUD 1945. Namun ada sebagian kelompok atau golongan yang menginginkan dan melakukan upaya untuk merubah dasar Negara Indonesia yang kita cintai ini dengan bentuk Negara Islam. Konsensus nasional menjadi panduan penting dalam menjaga persatuan dan kesatuan bangsa Indonesia dalam perjalanan sejarah sampai saat ini.Berbagai peristiwa penghianatan berupa pemberontakan, gerakan separatis, bahkan perjuangan politik yang legal melalui Konstituante, yang dilakukan oleh berbagai kelompok masyarakat untuk merubah atau mengganti konsensus tersebut dapat diatasi Hasil dari penelitian ini menunjukkan bahwa: Pondok pesantren ngalah tidak membeda bedakan baik santri yang bermukim dipondok maupun tidak. Mereka bisa saling belajar, bergaul, dan membantu antara satu dan lainnyadan mengakui perbedaan itu sebagai realitas. Kiai sholeh mewujudkan konsep hubungan antarumat beragama dengan formasi dialog yang sudah diselenggarakannya dengan mengadakan seminar nasional kerukunan antarumat beragama. Interpretasi dari seminar nasional adalah interaksi kiai sholeh dengan non muslim seperti doa bersama, silaturrohmi keagamaan, pentas seni, live in 100 pendeta, kerja sama dalam bidang pendidikan, peleburan budaya, dan aksi sosial pemuda bangsa Kata Kunci: Konsensus Kebangsaan,Pondok Pesantren

\section{PENDAHULUAN}

Konsensus bisa pula berawal hanya merupakan sebuah pendapat atau gagasan yang kemudian diadopsi oleh sebuah kelompok kepada kelompok yang lebih besar karena bedasarkan kepentingan (seringkali dengan melalui sebuah fasilitasi) hingga dapat mencapai pada tingkat konvergen keputusan yang akan dikembangkan. ${ }^{1}$

Konsensus nasional tersebut menjadi panduan penting dalam menjaga persatuan dan kesatuan bangsa Indonesia dalam perjalanan sejarah sampai saat ini.Berbagai peristiwa penghianatan berupa

${ }^{1}$ Saifuddin, A.F.Antropologi Kontenporer suatu Pengantar Kritis Mengenai Paradigma(Jakarta: Kencana 2006), 52 
pemberontakan, gerakan separatis, coup d'Etat, bahkan perjuangan politik yang legal melalui Konstituante, yang dilakukan oleh berbagai kelompok masyarakat untuk merubah atau mengganti konsensus tersebut dapat diatasi.

Oleh karena itulah kita perlu mengangkat kembali nilai-nilai kebangsaan khususnya nilai-nilai yang terkandung dalam konstitusi UUD NKRI Tahun 1945, demi meneguhkan kembali jati diri bangsa dan membangun kesadaran tentang sistem kenegaraan yang menjadi konsensus nasional, sehingga diharapkan bangsa Indonesia dapat tetap menjaga keutuhan dan mampu menegakkan kedaulatan Negara Kesatuan Republik Indonesia di tengah terpaan arus globalisasi yang bersifat multipdimensial.

Kemajemukan bangsa indonesia disebabkan hampir semua agama-agama besar, yakni Islam, Kristen Protestan, Katholik, Hindu, Budha dan Konghucu. Disisi lain indonesia juga terdiri dari beragam suku,etnis, budaya, dan bahasa. Bentuk negara kepulauan juga menyebabkan penghayatan dan pengamalan keagamaan bangsa ini untuk dibandingkan dengan bangsa-bangsa lain. ${ }^{2}$

Dalam sejarah, telah terjadi beberapa kekerasan dalam agama, kekejaman penganut Konfusianisme terhadap pengikut Buddhisme di Cina, nasib minoritas Islam diIndia, pengusiran orang-orang Yahudi pada zaman abad pertengahan Kristen. ${ }^{3}$ Masuknya agama yang dipahami secara sempit dan salah dalam wilayah konflik memiliki kerawanan amat tinggi. Dengan menggunakan label agama, konflik dan kerusuhan makin mudah berkobar dan menyebar. Pada titik ini ada hubungan erat antara pemahaman agama dan kekerasan politik. ${ }^{4}$

Konsensus Kebangsaan menjadi suatu kebutuhan yang tepat untuk menjawab kekhawatiran intoleransi, seperti yang sudah diterapkan oleh KH. M . Sholeh Bahruddin pendiri dan pengasuh di pondok pesantren ngalah. Pondok Pesantren Ngalah merupakan lembaga pendidikanyangindigenous yang tetap menjaga tradisi-tradisikearifan lokal yang tentunyatidakterlepas dari pola pikir seorangKiai yang mengasuhnya. Kiai sebagaitokoh yang memiliki posisi strategis dimasyarakat di wilayah Nusantara, Kiaijuga merupakan agen

\footnotetext{
${ }^{2}$ Riyadi, M.Irfan dan Basuki, Membangun Inklusivisme Faham Keagamaan, (Ponorogo: STAIN Ponorogo Press.2009), 2.

${ }^{3}$ Fredrich Heiler, "Studi Agama Seabagai Persiapan Kerjasama Antaragama" dalam A. Norma Permata, Metodologi Studi Agama, (Yogyakarta : Pustaka Pelajar, 2000), 223.

${ }^{4}$ Abd A'la, "Merajut Kembali Persatuan Bangsa," Kompas, 3 Agustus 2000.
} 


\section{4 :.: Konsensus Kebangsaan dalam Perspektif Pondok Pesantren Ngalah}

perubahandalam masyarakat. Setiap gagasanyang disampaikan selalu diresponspositif dan relatif akan ditaatimasyarakat, sebab kiai dimatamasyarakat dipandang sebagai sosokyang memiliki integritas; ada relevansidan konsistensi antara nilai-nilaiIslam yang disampaikan dengansikap dan perilaku kesehariannya.

Persoalan dialog agama muncul dari perkembangan hubungan sosial-kemanusiaan yang akhir-akhir ini mulai diperbincangkan, dialog agama sebagai entitas budaya akan merupakan agenda penting dan strategis, lebih-lebih lagi dalam perkembangan kemajemukan masyarakat. $^{5}$

Wawasan kebangsaan dalam kerangka NKRI, adalah cara bangsa Indonesia di dalam memandang diri dan lingkungannya untuk mencapai tujuan nasional yang mencakup perwujudan Kepulauan Nusantara sebagai kesatuan politik, sosial budaya, ekonomi dan pertahanan keamanan, dengan berpedoman pada falsafah Pancasila dan UUD 1945 atau dengan kata lain bagaimana memahami Wawasan Nusantara sebagai satu kesatuan politik, ekonomi, sosial, budaya dan pertahanan Keamanan.

Perjuangan Kyai Sholeh untuk memperkokoh kesatuan antar ummat beragama dilakukan dengan berbagai pola, diantaranya mengadakan seminar Nasional antar ummat beragama dengan menghadirkan Ibu Sinta Nuriah (Istri Gus Dur), KH. Said Aqil Siradj Ketua Umum PBNU, Romo Beni dan para elit Agama lain. Selain itu beliau juga menerbitkan beberapa buku yang berisi tentang multikulturalisme dan pluralisme agama.

Semua fenomena itu menandakan bahwa Kyai Sholeh sangat menghormati dan menghargai perbedaan agama. Dari beberapa perilaku Kyai Sholeh yang mengandung nilai-nilai pluralistik berharap agar dapat menciptakan kerukunan hidup antar ummat beragama. Mengajarkan santri bagusi kabeh konco cilik gedhe lanang wadon, jangan membedabedakan ras, suku, agama, karna pondok ngalah adalah rohmatallil alamin. Santri pun bermacam-macam mulai dari jawa sampai luar jawa. Karna bukanlah indonesia jika tanpa Kristen, Hindu, Budha, konghucu, dan Islam. ${ }^{6}$

\footnotetext{
${ }^{5}$ Munir Mulkhan, “ Agama Dalam Dialog Budaya”, dalam Andito (ed.), Atas Nama Agama, h, 281-283.

${ }^{6}$ Wawancara kyai Sholeh Bahruddin, sabtu 3 februari 2019
} 
K.H. M. Sholeh Bahrudin konsisten dalam memperjuangkan ajaran dan sikap pluralisme di Pondok Pesantren Ngalah.Pertama, dibuktikan dengan tingginya praktik toleransi umat beragama di tengahtengah Pondok Pesantren Ngalah.Kedua, Pondok Pesantren Ngalah teguh dalam menjalin kerukunan umat beragama.Secara spesifik, keterlibatan Kiai Sholeh dalam membangun kerukunan umat beragama di kabupaten Pasuruan ini, menjadi bukti secara nyata dan harus dilanjutkan secara estafet oleh para santri.

Kegiatan lintas agama dan budaya, seperti halnya seminar nasional membangun kerukunan umat beragama, yang dihadiri berbagai tokoh lintas agama sering diselenggarakan dan diadakan oleh Yayasan Darut Taqwa, begitu juga dengan silaturahmi keagamaan, dimana Yayasan Darut Taqwa dan lembaganya sering melakukan kunjungankunjungan ke berbagai gereja, vihara dan tempat-tempat ibadah yang lainnya, hal ini tidak lain adalah sebagai bentuk komitmen bahwa Pondok Pesanren yang ingin membangun kerukunan antar umat beragama dengan tujuan supaya tidak terjadi perang saudara di bumi tecinta ini.

Dari kegiatan seminar nasional kerukunan antar umat beragama tersebut telah dihasilkan sebuah buku yang berjudul "SERUMPUN BAMBU (Jalan Menuju Kerukunan Sejati)".7Dengan adanya buku tersebut bisa menjembatani komunikasi antar agama agar memahami perbedaan sebagai upaya dalam menciptakan kehidupan harmonis antar umat beragama. Berikut penyampaian Kyai Sholeh terkait dengan seminar dengan tujuan demi kerukunan antar umat beragama tersebut: "Demi bangsa dan Negara biar aman tentram dan damai, Darut-Taqwa memberanikan diri mengadakan seminar untuk merukunkan semua umat.Jadi semua delegasi semua agama saya undang untuk menghadiri seminar.

Berdasarkan fenomena di atas judul penelitian ini adalah"Konsensus Kebangsaan dalam Pemikiran Pondok Pesantren Ngalah"

\section{PEMBAHASAN}

\footnotetext{
${ }^{7}$ Seminar Kebangsaan, Term Of Reference Penyusunan dan Penerbitan Buku, http://seminar2010.daruttaqwa.or.id/search/label/TOR, diakses pada tanggal 14 Oktober 2018.
} 


\section{Pancasila dalam Perspektif Pondok Pesantren Ngalah}

1. Ketuhanan Yang Maha Esa

Pada sila pertama ini mengandung ajaran ketauhidan dalam pengertian keimanan kepada Tuhan Yang Maha Esa. Menurut Kiai Sholeh dalam rangka menciptakan kerukunan dan keharmonisan antarumat beragama diantaranya adalah dengan melakukan do'a bersama.

2. Kemanusiaan yang Adil Dan Beradab

Sila kedua ini mencerminkan nilai kemanusiaan yang menjunjung tinggi sikap adil dan beradab.Pondok Pesantren Ngalah merupakan salah satu medan budaya penciptaan kerukunan antar umat beragama. Melalui pentas seni yang digelar dipondok pesantren Kiai Sholeh berharap dapat menjalin keharmonisan antarumat beragama. Berdasarkan dokumen-dokumen, Pentas seni yang pernah digelar di pondok pesantren diantaranya adalah konser Iwan Fals yang dibuka oleh Kiai Sholeh bersama elitagama,pertunjukan barongsai yang bekerja sama dengan elit agama konghuchu, paduan suara antarumat beragama, wayang kulit, dan ludruk.

3. Persatuan Indonesia

Sila ketiga ini menggambarkan sebuah kehidupan yang rukun, damai, saling berdampingan dalam bingkai keanekaragaman bangsanya dengan dilandasi persatuan serta kebersamaan, Pondok Pesantren Ngalah sudah didatangi oleh live in 100 pendeta merupakan bentuk keterpanggilan dan kepedulian oleh Kiai Sholeh dan Pendeta Simon Filantropha, M. Th dari Gereja Kristen Indnonesia (GKI) untukmembangun toleransi antarumat beragama.

Kiai Sholeh menyambut 100 pendetadari GKI di Masjid Aminah Pesantren. Bertepatan dengan acara rutinan pengajian senenan. Senenan adalah pengajian yang diasuh oleh Kiai Sholeh setiap senin malam. Kegiatan ini diawali dengan salat isya' berjama'ah kemudian dilanjutkan salah sunnah tobat, lidaf'il bala' dan salat hajat. Setelah itu Kiai Sholeh memberi mauidhoh hasanah kepada para jama'ah. Selanjutnya,mereka diajak menyaksikan pengajian senenan yang diikuti sekitar 3.000 jamaah. Bahkan, pimpinan rombongan yakni Pdt. Simon Filantropa mendapat kesempatan untuk menyampaikan sambutannya dimasjid Aminah.

4. Kerakyatan Yang Dipimpin Oleh Hikmat Kebijaksanaan DalamPermusyawaratan Perwakilan 
Sila yang memberi petunjuk dalam pelaksanaan kepemimpinan serta dalam mengambil sebuah keputusan itu harus secara bijak dengan tetap berdasarkan musyawarah. Kegiatan ini diprakarsai oleh santri pondok pesantren Ngalah dan pemuda GKJW (Gereja Kristen Jawi Wetan). Setelah terselenggaranya seminar agama yang laksanakan oleh Kiai Sholeh dan elit agama. Ada satu masukan dari salah satu pendeta yakni Pdt. Sihardi. Usulan tersebut agar mengadakan kegiatan pemuda yang melibatkan antar umat beragama, yang diwadahi oleh golongan muda. Kalau seminar agama golongan tua tapi untuk aksi sosial pemuda bangsa adalah golongan muda. Bahwa dalam aksi ini terbentuklah 2 kegiatan utama yaitu :

1) Layanan Kesehatan Gratis

Layanan kesehatan merupakan salah satu kegiatan yang diadakan oleh pemuda GKJW dan santri pondok pesantren ngalah. Layanan kesehatan ini dikembangkan untuk membinan kerukunan antarumat beragama. Layanan Kesehatan ini diselenggarakan dipondok pesantren Ngalah dalam bentuk penyakit ringan seperti panas, batuk, maag, dan lainsebagainya.

2) Tanam Pohon

Kegiatan kedua yang dikawal oleh pemuda GKJW dan santri pondok pesantren Ngalah adalah tanam pohon. Dana untuk pembelian pohon dari iuran bersama. Tanam pohon ini dilakukan disekitar desa Pandean-Kembangkuning.

5. Keadilan Sosial Bagi Seluruh Rakyat Indonesia

Sila yang menggambarkan dan mencita-citakan terwujudnya kehidupan yang adil, makmur, bagi seluruh rakyatnya yang beraneka ragam. Pengurus pondok pesantren Ngalah kedatangan pelajar dari Australia adalah untuk mempelajari bahasa Indonesia dan dapat belajar percakapan langsung dengan orang Indonesia. Mereka adalah pelajar dari school collage Australia, disana mereka mengambil jurusan bahasa Indonesia. Selain itu tujuan mereka adalah mengenal budaya Indonesia yang beragam dan mayoritas beragama islam. Mereka sering mendengar dari media massa bahwa agama islam adalah agama keras, suka mengebom atas nama jihad $f i$ sabillilah. Tapi setelah live in dipondok pesantren selama beberapa hari mereka berkesimpulan bahwa islam itu rukun, penyayang, damai, dan tidak keras.

\section{Konsensus kebangsaan NKRI dalam Perspektif Pondok Pesantren Ngalah}


Kiai Sholeh juga menjelaskan jika berbicara dasar Negara Kesatuan Republik Indonesia (NKRI), tentu tidak lain adalah Pancasila. Dimana Pancasila yang mengandung nilai-nilai universal dengan prinsip "Bhinneka Tunggal Ika"nya, itu digali dari bumi pertiwi dan disepakati sebagai konsensus nasional untuk menjadi dasar NKRI dan menjadi payung kehidupan bersama dalam berbagai perbedaan. Di sisi lain, terjadinya konflik dan ketegangan di beberapa kawasan Republik Indonesia pada era setelah reformasi membuktikan bahwa kurang hati-hatinya negara kita dalam mengelola kemajemukan bangsa ini, dan ini kalau kita biarkan dapat membahayakan keutuhan bangsa itu sendiri. Dengan demikian yang menjadi tantangan bersama saat ini adalah bagaimana kita dapat mewujudkan potensi dan simbol-simbol ke-bhineka-an dalam perspektik ketahanan sosial-budaya tanpa mengorbankan cita-cita reformasi itu sendiri.

Namun, di sisi lain kita juga pernah mendapatkan keterangan dari beberapa kelompok bahwa Pancasila sebagai dasar negara itu sudah tidak relevan untuk mengatasi problem bangsa ini karena menurut kesimpulan mereka Pancasila tidak sesuai dengan ketentuan Tuhan (agama Islam). Menurut Kiai Sholeh itu merupakan sebuah kesimpulan yang terburu-buru, dan sebuah pemikiran yang sangat sempit dan dangkal.Karena Pancasila sebagai dasar Negara Indonesia sebenarnya sudahlah sangat Islami (sesuai dengan tuntunan agama Islam).Sebagai bentuk komitmen dan sekaligus untuk mempertahankan dan menjaga kokohnya NKRI ini. Kiai Sholeh Bahruddin mengeluarkan beberapa maklumat sebagai berikut:

Negara Indonesia terdiri dari berbagai pulau, suku, seni dan budaya, bahasa, dan agama yang berbeda-beda. Perbedaan tersebut merupakana satu kesatuan dalam bingkai Negara Kesatuan Republik Indonesia yang berasaskan Pancasila dan UUD 1945. Namun ada sebagian kelompok atau golongan yang menginginkan dan melakukan upaya untuk merubah dasar Negara Indonesia yang kita cintai ini dengan bentuk Negara Islam. Pada intinya menurut kyai sholeh ambagusi kabeh konco cilik gedhe lanang wadon,enom tuwo lan gawe kebagusan opo ae makhluke pengeran.

\section{Konsensus kebangsaan Bhinneka Tunggal Ika dalam Perspektif Pondok Pesantren Ngalah}


Pondok Pesantren Ngalah tidak membeda-bedakan santri yang bermukim maupun tidak, baik ras, suku, tetapi satu jua. Secara mendalam Bhinneka Tunggal Ika memiliki makna walaupun di Indonesia sebagai negara yang multikultural, di mana terdapat banyak suku, agama, ras, kesenian, adat, bahasa, dan lain sebagainya namun tetap satu kesatuan yaitu sebangsa dan setanah air. Dipersatukan dengan bendera, lagu kebangsaan, mata uang, bahasa dan lain sebagainya.

\section{Konsensus kebangsaan UUD dalam Perspektif Pondok Pesantren Ngalah}

Pondok Pesantren Ngalah itu lebih dominan pada UUD Pasal 28 terkait Hak Asasi Manusia.Pondok Pesantren Ngalah sangat mengajarkan nilai-nilai kemanusian untuk menciptakan harmonisasi dan integritas Negara Kesatuan Republik Indonesia.Di samping itu, Pondok Pesantren Ngalah mengajarkan sikap toleransi yaitu sikap saling mengahargai dan menghormati setiap Hak pada masing-masing individu.Meskipun pesantren yang khas dengan nilai-nilai ke-Islamman Pondok Pesantren Ngalah menghormati hak orang lain untuk tanpa memeluk agamanya memaksa dan menghalangi orang lain beragama sesuai keyakinannya. Pondok Pesantren Ngalah juga menekan hak politik santrinya, artinya Kyai Soleh memberikan hak kepada seluruh santri putra dan santri putri untuk menggunakan hak pilih sesuai dengan kehendak santri-santrinya tanpa menyodorkan dan memaksa memilih calon tertentu untuk di pilih. Selain itu UUD 45 dalam Pondok Pesantren Ngalah di jadikan sebagai dasar hukum untuk dijadikan pedoman Pondok Pesantren Ngalah.UUD 45 dalam Pondok Pesantren Ngalah bersifat mutlak di taati untuk menjaga eksistensi NKRI dan memperkuat nilai-nilai Bhinneka Tunggal Ika.

\section{KESIMPULAN}

Adapun kesimpulan penelitian dapat penulis deskripsikan sebagai berikut:

1. Pancasila dalam Pandangan Pondok Pesanren Ngalah adalah Sebagai payung kebersamaan, berpegang teguh pada lima sila dan tidak mengikui idiologi lain.

2. NKRI dalam Pandangan Pondok Pesanren Ngalah adalah Harga mati bagi Pondok Pesanren Ngalah tidak membeda - bedakan 
agama, pulau, suku, seni dan budaya, bahasa. Menurut kyai sholeh ambagusi kabeh konco cilik gedhe lanang wadon,enom tuwo lan gawe kebagusan opo ae makhluke pengeran.

3. UUD dalam Pandangan Pondok Pesanren Ngalah adalah sebagai dasar hukum untuk dijadikan pedoman pondok pesantren. Kepada seluruh santri putra dan santri putri untuk menggunakan hak pilih sesuai dengan kehendak santri-santrinya tanpa menyodorkan dan memaksa memilih calon tertentu untuk di pilih.

4. Binneka Tunggal Ika dalam Pandangan Pondok Pesanren Ngalah adalah Semboyan sebagai modal untuk bersatutidak membeda-bedakan santri yang bermukim maupun tidak, baik ras, suku, tetapi satu jua. Dipersatukan dengan bendera, lagu kebangsaan, mata uang, bahasa dan lain sebagainya.

\section{DAFTAR PUSTAKA}

A'la, Abd. 2000. Merajut Kembali Persatuan Bangsa.Kompas, 3 Agustus 2000.

Anshari, Syaifuddin dan Endang. 2001. Sebuah Konsensus Tentang Dasar Negara Republik Indonesia (1945-1949).Bandung: Gema Insani Press.

Basuki dan M.Irfan. 2009. Membangun Inklusivisme Faham Keagamaan, Ponorogo: STAIN Ponorogo Press.

Burhani, Ahmad dan Najib. 2001. Islam Dinamis: menggugat peran agama membongkardoktrin yang membantu. Jakarta:Kompas Media Nusantara.

Depag RI. 2006. Al-Qurann dan Terjemahanya. Kudus: Menara Kudus .

Hasan, Zulkifli . 2016. Pancasila Perspektif Khalayak dan Sosial Media. sanggung seto.

Heiler, Fredrich. 2000. Metodologi Studi Agama.Yogyakarta : Pustaka Pelajar. 
Mulkhan, Munir. Agama Dalam Dialog Budaya dalam Andito (ed.), Atas Nama Agama.

Mustansyir,Rizal. 1995. Bhinneka Tunggal Ika dalam Perspektif FilsafatAnalitik.Jurnal Filsafat: Yogyakarta.

Pondok Pesantren Ngalah. 2008. Buku Pedoman Santri Darut Taqwa dalam Berbangsa dan Bernegara.Piagam Madina. Pasuruan: Yudharta Advertaising Design.

Saifuddin, A.F. 2006. Antropologi Kontenporer suatu Pengantar Kritis Mengenai Paradigma. Jakarta: Kencana.

Sarifuddin HA (ed.) dan Kurniawan Zein. 2001. Syariat Islam Yes Syariat Islam Dilema Piagam Jakarta dalam Amandemen UUD 1945. Jakarta : Paramadina. 